\title{
Perbedaan Aktivitas Larvisida Antara Ekstrak Metanol, Etil Asetat dan Kloroform Rimpang Zingiber zerumbet (L) Smith pada Aedes aegypti (Diptera: Culicidae)
}

\author{
Comparison of Methanol, Ethyl Acetates and Chloroform Extracts of Zingiber \\ zerumbet (L) Smith in Larvisidal Activities on Aedes aegypti (Diptera: \\ Culicidee) Larvae
}

\section{Tri Murini1 ${ }^{*}$, Mae Sri Hartati Wahyuningsih1, Tri Baskoro T.Satoto}

1. Departemen Farmakologi dan Terapi

2. Departemen Parasitologi, Fakultas Kedokteran Kesehatan Masyarakat dan Keperawatan, Universitas Gadjah Mada, Yogyakarta

Corresponding author: Tri Murini: Email: murini28@yahoo.co.id

\begin{abstract}
ABSTRAK
Akhir-akhir ini banyak ditemukan bahwa larva nyamuk telah resisten terhadap larvisida konvensional. Oleh karena itu, perlu dikembangkan larvisida baru dari bahan alam. Salah satu bahan alam yang dapat digunakan sebagai larvisida adalah rimpang $Z$. zerumbet, yang pada penelitian sebelumnya berpotensi sebagai larvisida pada Artemia salina Leach dan Anopheles nunestovary. Penggunaan beberapa solven untuk melihat aktivitas larvisida terbaik pada $Z$. zerumbet belum pernah diteliti. Tujuan penelitian ini untuk mengkaji aktivitas larvisida ekstrak methanol, etil asetat dan kloroform pada $A$. aegypti. Penelitian ini merupakan penelitian eksplorasi laboratories dengan rancangan posttest-only control group. Penelitian dilakukan pada tiga macam ekstrak Z. zerumbet dengan perbedaan solven yaitu methanol, etil asetat dan kloroform. Dua puluh lima larva instar III-IV Aeaegypti dipejankan dengan tujuh konsentrasi yang berbeda dari ketiga ekstrak rimpang $Z$. zerumbet. Tingkat kematian larva dihitung dan kemudian dianalisis menggunakan regresi analisa probit untuk mendapatkan nilai $\mathrm{LC}_{50}$ dan $\mathrm{LC}_{90}$. Nilai $\mathrm{LC}_{50}$ dan LC $_{90}$ ketiga ekstrak methanol; etil asetat dan kloroform adalah; 153,57; 185,80; 3542,03 ppm dan; 226,$59 ; 274,70 ; 5567,24$ ppm. Ekstrak methanol rimpang Z. zerumbet memiliki aktivitas larvisida yang kuat terhadap larva instar III-IV Ae.aegypti dibandingkan dengan ekstrak lainnya.
\end{abstract}

Kata kunci: Ekstrak, Z.zerumbet, larvisida, Ae.aegypti, $\mathrm{LC}_{50}$

\begin{abstract}
The resistance of mosquito larvae to conventional larvicides has been increased in the recent years. Therefore, it is necessary to develop new larvacides from natural materials. Previous studies showed that Zingiber zerumbet (L.) Smith has a potential ability as a larvicide in Artemia salina Leach and Anopheles nunestovary. Nevertheless, the use of different solvents to observe the best larvicidal activity has not been known. This study aims to assess the larvicidal activity of methanol extract, ethyl acetate, and chloroform in Aedes aegypti larvae. This is an exploratory laboratory study with the posttest-only control group. The extraction solvents used were methanol, ethyl acetate, and chloroform. Twenty-five instar larvae (III-IV) of Ae.aegypti were treated with seven different concentrations of the three Z rhizome extracts. The mortality rate of the larvae was calculated and analyzed using probit analysis regression to obtain $\mathrm{LC}_{50}$ and $\mathrm{LC}_{90}$ values. The $\mathrm{LC}_{50}$ of the methanol, ethyl
\end{abstract}


acetate, and chloroform extracts are 153.57, 185.80, $3542.03 \mathrm{ppm}$; while the $\mathrm{LC}_{90}$ are $226.59,274.70$, and $5567.24 \mathrm{ppm}$, respectively. The study suggested that the methanol extract of $Z$. zerumbet rhizome has the most robust larvicidal activity against third-fourth instar larvae of Ae. aegypti among other extracts.

Key words: Extract, Z.zerumbet, larvisidal, Ae.aegypti, $\mathrm{LC}_{50}$

\section{PENDAHULUAN}

Nyamuk Aedes aegypti merupakan vektor utama penyebab demam berdarah dengue di Indonesia. Untuk mengantisipasi penyebarannya sebaiknya diberantas pada waktu masih dalam bentuk larva. Pemberantasan larva nyamuk dengan larvisida hingga kini masih menggunakan temefos (Abate). Pemakaian insektisida secara terus menerus dalam waktu lama dapat mengakibatkan resistensi organisme sasaran. Resistensi larva Ae. agypti terhadap temefos telah dilaporkan di Indonesia, didaerah Surabaya (Mulyatno et al., 2012) dan di Jakarta (Prasetyowati et al.,2016) sementara di luar negeri juga terjadi di Colombia dan Brazil (Grizales et al., 2013; Diniz et al., 2014). Insektisida yang aman terhadap lingkungan adalah insektisida yang secara selektif toksik terhadap serangga sasaran, dan mudah mengalami biodegradasi di alam sehingga dapat digunakan pada manajemen program pengendalian serangga sasaran (Rattan, 2010). Penggunaan produk bioaktif alami dengan potensi larvisida perlu dikembangkan sebagai alternatif pencegahan berkembangnya larva

Lempuyang gajah (Zingiber zerumbet (L) J.E.Smith), merupakan tanaman obat yang sering digunakan sebagai campuran jamu dalam industri obat tradisional. Kandungan kimia lempuyang gajah antara lain senyawa golongan terpenoid (zerumbon, zederon), alkaloid, fenol termasuk flavonoid (derivat kaempferol) dan komponen aromatik (Phidroksibezaldehid, vanilin) serta saponin (Dae et al., 2004; Chien et al., 2008; Hashemi et al., 2008). Skrining pendahuluan pada beberapa tanaman sebagai larvisida te rhadap larva Ae aegypti menunjukan bahwa ekstrak metanol rimpang Z.zerumbet mempunyai aktivitas larvisida terbaik dengan nilai $\mathrm{LC}_{50}$ : 153,57ppm (Murini et al., 2014)

\section{METODOLOGI \\ Bahan dan alat}

Bahan tanaman yang digunakan adalah rimpang Z.zerumbet diperoleh dari desa Jatimulyo, Kulon Progo yang diambil bulan Mei 2014 dan telah diterminasi di Bagian Biologi Fakultas Farmasi Universitas Gadjah Mada (BF/284/Ident/Det/VI/2014) metanol standart teknis, kloroform standart teknis, etil acetat standart teknis, wash benzen standart teknis, silika gel $\mathrm{GF}_{254}$, larva instar III-IV nyamuk Ae. aegypti Lampu UV (254 dan $366 \mathrm{~nm}$ ), reagen penyemprot (Cerium Sulfat ), sentrifuge (Hitachi 18PR/5, Automatic high speed refrigerated), vakum evaporator (Heidolf $\mathrm{vv}$ 2000, Germany) ,oven (Memert, Germany), plate silica gel $\mathrm{GF}_{254}$, gelas volume $250 \mathrm{ml}$, air suling.

\section{Cara penelitian}

Preparasi ekstrak metanol, etil asetat dan kloroform rimpang Z.zerumbet

Masing-masing 500 gram serbuk kering rimpang lempuyang gajah diekstraksi dengan cara maserasi disertai pengadukan selama 24 jam pada suhu kamar menggunakan 1 liter metanol; 1 liter ethyl asetak dan 1 liter kloroform. Penyaringan dilakukan menggunakan corong buchner dan ampasnya dimaserasi kembali dengan cara yang sama sebanyak dua kali kemudian disaring. Filtrat yang didapat digabung pada masing-masing solven dan diuapkan, sehingga diperoleh 
ekstrak metanol, ekstrak etil asetat dan ekstrak kloroform dalam konsistensi kental, kemudian ditimbang untuk mengetahui rendemennya. Keberhasilan masing-masing ekstraksi dipantau dengan metode Kromatografi Lapis Tipis (KLT).

\section{Kolonisasi larva Aedes agypti}

Proses kolonisasi larva nyamuk $A e$. aegypti dilakukan di Laboratorium Parasitologi Fakultas Kedokteran Kesehatan Masyarakat dan Keperawatan Universitas Gadjah Mada dengan metode sesuai prosedur yang ada menurut WHO (2005 ). Nyamuk Ae.aegypti dewasa dipindahkan ke sangkar nyamuk dengan menggunakan aspirator. Didalam sangkar disediakan mangkok yang berisi air leding sebagai tempat bertelur nyamuk. Selanjutnya telur Ae.aegypti dimasukkan dalam baki yang berisi $1500 \mathrm{ml}$ air sumur dan ditunggu 1-2 hari sampai menetas menjadi larva. Selama proses kolonisasi, diberikan hati ayam sebagai makanan larva. Identifikasi larva instar III-IV Ae.aegypti dilakukan 7 hari setelah menetas, secara makroskopis dengan menggunakan lensa pembesar.

\section{Uji aktifitas larvisida}

Penelitian ini menggunakan tujuh konsentrasi untuk ekstrak metanol dan etil asetat $(125 ; 135 ; 145,80 ; 157,46 ; 170,06$; 183,67 dan $200 \mathrm{ppm})$, sedangkan ekstrak kloroform (2500; 2800; 3136; 3933,85; 4495,85 dan 5000 ppm). Masing-masing konsentrasi ekstrak disuspensikan dengan tween 80 beberapa tetes, kemudian diberi air hingga $100 \mathrm{ml}$ dimasukkan dalam wadah plastik yang bervolume $200 \mathrm{ml}$. Tiap wadah berisi 25 ekor larva instar III- IV Ae. aegypti. Perhitungan larva yang mati dilakukan 24 jam setelah pemberian ekstrak. Larva dinyatakan mati apabila tenggelam atau tidak bergerak setelah diganggu atau disentuh dengan pipet pada sifon atau daerah toraks (WHO,2005). Pengujian diulang sebanyak tiga (3) kali.

\section{Analisa data}

Aktivitas larvisida digambarkan dengan nilai $\mathrm{LC}_{50}$ dan $\mathrm{LC}_{90}$ yang ditetapkan dengan regresi analisis probit menggunakan program A.Woods U.N.S.W. versi 1.1.

\section{HASIL DAN PEMBAHASAN}

Hasil Preparasi ekstrak metanol, etil asetat dan kloroform rimpang $Z$. zerumbet

Rimpang Z.zerumbet yang telah dibuat serbuk dan dilakukan dengan metode maserasi karena rimpang Z.zerumbet mengandung minyak mudah menguap. Maserasi dilakukan dengan menggunakan solven yang berbeda kepolarannya yaitu metanol (polar), etill asetat (semi polar) maupun kloroform (non polar) masing-masing selama 3 hari. Hasil ekstraksi dari beberapa solven yang berbeda kepolarannya dari rimpang Z.zerumbet disajikan pada (Tabel 1). Hasil ekstraksi dengan solven metanol, etil asetat dan kloroform dari serbuk rimpang Z.zerumbet secara masera menghasilkan rendemen $0,75 \%, 1,26 \%$ dan $7,25 \%$. Pada (Tabel 1) terlihat bahwa ekstraksi dengan pelarut metanol pada rimpang Z.zerumbet menghasilkan rendemen paling kecil dibandingkan dengan pelarut etil asetat dan kloroform. Hal ini menunjukkan bahwa kandungan kimia yang terdapat pada pelarut polar paling kecil dibandingkan dengan pelarut semi polar maupun non polar.

\section{Hasil Kromatogram ekstrak metanol, etil asetat dan kloroform}

Profil kromatogram pada KLT terlihat adanya spot yang tebal pada ekstrak metanol (I) yang menunjukkan bahwa senyawa yang tersari pada ekstrak methanol lebih banyak dibandingkan Dengan ekstrak etil asetat maupun kloroform (Gambar 1). Dapat diartikan bahwa senyawa yang terkandung dalam solven metanol yang bersifat polar lebih 
Tabel I. Hasil rendemen dari serbuk rimpang Z. zerumbet dengan metode maserasi

\begin{tabular}{lcc}
\hline Macam & Bobot kering (kg) & Rendemen \% \\
\hline Ekstrak metanol & 0,5 & 0,75 \\
Ekstrak etil asetat & 0,5 & 1,26 \\
Ekstrak kloroform & 0,5 & 7,25 \\
\hline
\end{tabular}

$\overline{\text { Keterangan : \% Redemen diperoleh dari berat ekstrak dengan bobot tetap dibagi dengan }}$ berat serbuk

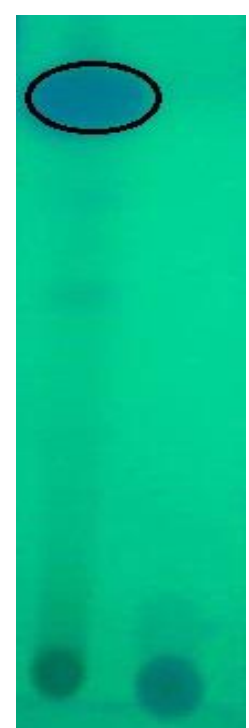

I

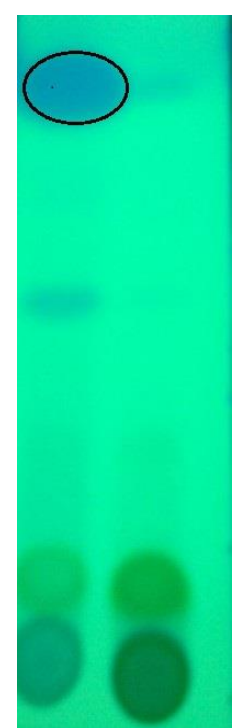

II

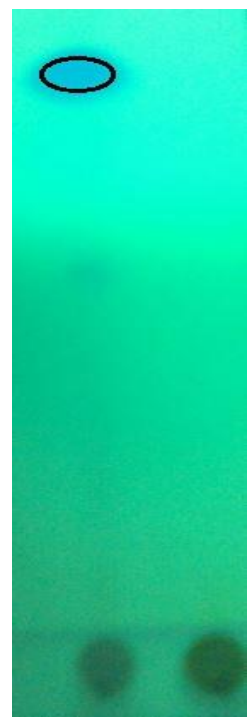

III

Gambar1: Kromatogram KLT ekstrak metanol (I); ekstrak etil asetat (II) dan ekstrak kloroform dari rimpang Z. zerumbet; Fase diam: silika gel GF254; fase gerak: Etil asetat $: \mathrm{WB}=1: 3$; Deteksi dengan sinar UV $254 \mathrm{~nm}$

besar dibandingkan dengan solven semi polar maupun non polar.

Ekstraksi rimpang Z.zerumbet dengan pelarut metanol bertujuan untuk mendapatkan golongan senyawa yang bersifat polar, sedangkan pelarut etil asetat untuk mendapatkan golongan senyawa yang bersifat semi polar, serta kloroform untuk mendapatkan golongan senyawa yang bersifat non polar. Dilihat dari profil KLT ekstrak dengan pelarut non polar menunjukkan spot yang tidak tebal, yang dapat diartikan bahwa senyawa-senyawa yang terlarut pada solven bersifat non polar hanya tersari sedikit atau golongan senyawa yang bersifat non polar hanya kecil. Sementara dengan solven etil asetat memberikan spot yang lebih tebal dibanding dengan solven kloroform. Dalam hal ini etil asetat merupakan solven semi polar yang mendekati polar.

\section{Hasil Uji daya Larvisida ekstrak metanol, etil asetat dan kloroform Z.zerumbet}

Uji larvisidal secara in vivo pada larva Ae.aegypti terhadap ekstrak metanol, etil asetat dan kloroform dengan tujuan untuk mengetahui aktivitas larvisida dari setiap ekstrak yang diperoleh. Untuk mengetahui aktivitas larvisida, masing-masing ekstrak dipaparkan pada larva Ae.aegypti stadium III-IV selama 24 jam.

Aktivitas larvisida dihitung berdasarkan kematian larva. Hasil uji aktivitas menunjukkan persentase kenaikkan kematian larva Ae.aegypti pada 
Tabel II. Nilai $\mathrm{LC}_{50}$ dan $\mathrm{LC}_{90}$ pada ekstrak metanol, etil asetat dan kloroform

\begin{tabular}{|c|c|c|c|c|c|c|}
\hline $\begin{array}{c}\text { Nama } \\
\text { ekstrak }\end{array}$ & $\begin{array}{c}\text { Konsentrasi } \\
{ }^{\mathrm{a}}(\mathbf{p p m})\end{array}$ & $\begin{array}{l}\text { Jumlah } \\
\text { larva }\end{array}$ & $\begin{array}{l}\text { bKematian } \\
\text { (\%) }\end{array}$ & $\begin{array}{l}\text { Slope } \\
( \pm \text { SE })\end{array}$ & $\begin{array}{c}\mathrm{LC}_{50} \\
\text { (ppm) } \\
(95 \% \mathrm{CL})\end{array}$ & $\begin{array}{c}\text { LC }_{90} \\
\text { (ppm) } \\
(95 \% \mathrm{CL})\end{array}$ \\
\hline \multirow[t]{9}{*}{ Metanol } & kontrol & 25 & $0,00 \pm 0,00$ & & & \\
\hline & 125,00 & 25 & $24,00 \pm 1,89$ & & & \\
\hline & & & & 7,61 & 153,57 & 226,59 \\
\hline & 135,00 & 25 & $33,33 \pm 3,93$ & $( \pm 0,23)$ & $\begin{array}{c}*(144,57- \\
163,13)\end{array}$ & $\begin{array}{c}*(193,26- \\
269,07)\end{array}$ \\
\hline & 145,80 & 25 & $49,33 \pm 2,88$ & & & \\
\hline & 157,46 & 25 & $48,67 \pm 1,45$ & & & \\
\hline & 170,06 & 25 & $62,67 \pm 2,18$ & & & \\
\hline & 183,67 & 25 & $70,67 \pm 4,36$ & & & \\
\hline & 200,00 & 25 & $80,00 \pm 1,89$ & & & \\
\hline \multicolumn{7}{|l|}{ Etil asetat } \\
\hline & kontrol & 25 & $0,00 \pm 0,00$ & & & \\
\hline & 125,00 & 25 & $9,33 \pm 1,89$ & & & \\
\hline & & & & 7,57 & 185,80 & 274,70 \\
\hline & 135,00 & 25 & $13,33 \pm 1,89$ & $( \pm 0,29)$ & $\begin{array}{c}*(170,69- \\
202,28)\end{array}$ & $\begin{array}{c}*(218,05- \\
346,27)\end{array}$ \\
\hline & 145,80 & 25 & $21,33 \pm 1,89$ & & & \\
\hline & 157,46 & 25 & $33,33 \pm 3,27$ & & & \\
\hline & 170,06 & 25 & $44,00 \pm 3,27$ & & & \\
\hline & 183,67 & 25 & $49,33 \pm 1,89$ & & & \\
\hline & 200,00 & 25 & $54,67 \pm 4,99$ & & & \\
\hline \multicolumn{7}{|l|}{ Kloroform } \\
\hline & kontrol & 25 & $0,00 \pm 0,00$ & & & \\
\hline & 2500 & 25 & $18,67 \pm 1,86$ & & & \\
\hline & 2800 & 25 & $32,00 \pm 9,80$ & $\begin{array}{c}7,60 \\
( \pm 9,50)\end{array}$ & $\begin{array}{c}3542,03 \\
(3298,41- \\
3803,75)\end{array}$ & $\begin{array}{c}5567,24 \\
(4712,51- \\
6580,59)\end{array}$ \\
\hline & 3136 & 25 & $40,00 \pm 14,24$ & & & \\
\hline & 3512,32 & 25 & $52,00 \pm 6,53$ & & & \\
\hline & 3933,85 & 25 & $64,00 \pm 5,66$ & & & \\
\hline & 4495,85 & 25 & $77,33 \pm 3,77$ & & & \\
\hline & 5000 & 25 & & & & \\
\hline
\end{tabular}

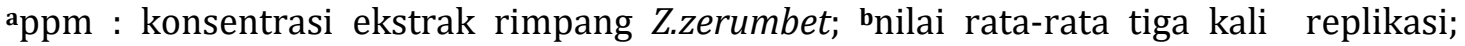
${ }^{*}$ confidencelimit 95\% (LCL= Lower Confidence Limit; UCL = Under Confidence Limit)

masing-masing kadar ekstrak (Tabel II).

Makin tinggi konsentrasi ekstrak uji maka \% kematian larva makin besar. Pada Tabel 2 menunjukkan konsentrasi ekstra terkecil pada metanol dan etil asetat $(125$ ppm) mampu mematikan larva Ae.aegypti sebesar 24,00 $\pm 1,89$ dan $9,33 \pm 1,89 \%$. Pada konsentrasi $200 \mathrm{ppm}$ mampu mematikan larva secara berturut-turut $80,00 \pm 1,89$ dan $85,33 \pm 3,77 \%$. Sedangkan untuk solven non polar (kloroform) konsentrasi terendah (2500 ppm) hanya bisa mematikan $18,67 \pm 1,86 \%$. Hasil perbedaan kelarutan senyawa aktif rimpang Z.zerumbet terhadap sifat polaritas solven yang diujikan pada larva Ae.aegypti instar III-IV ternyata juga mempengaruhi nilai $\mathrm{LC}_{50}$ dan $\mathrm{LC}_{90}$ pada masing-masing solven. Senyawa yang larut dalam solven polar yaitu metanol memberikan hasil $\mathrm{LC}_{50}$ dan $\mathrm{LC}_{90}$ lebih kecil 
dibandingkan dengan solven semi polar (etil asetat) dan non polar (kloroform), yaitu 153,57; 185,80; 3542,03 ppm dan 226,59; 274,70 dan 5567,24ppm. Hal ini dapat diartikan bahwa nilai $\mathrm{LC}_{50}$ dan $\mathrm{LC}_{90}$ memberikan hasil yang lebih poten terhadap larva Aeaegypti dibandingkan nilai $\mathrm{LC}_{50}$ dan $\mathrm{LC}_{90}$ yang besar.

Hasil yang sama pada beberapa penelitian yang dilakukan pada daun Morinda citrifolia; Azadirachta indica; Delonix elata; Mirabilis jalapa; Tridax procumbens (Kovendan et al., 2012; Maragathavalli et al., 2012; Gavindarajan et al., 2014; Begum et al., 2014) dengan solven polar (metanol) memberikan hasil $\mathrm{LC}_{50}$ dan $\mathrm{LC}_{90}$ lebih kecil dibanding solven semi polar (etil asetat) maupun non polar (kloroform, heksan, benzen). Hal ini dapat diartikan bahwa zat aktif yang terdapat pada rimpang Z.zerumbet mempunyai khasiat sebagai larvisida pada larva Ae.aegypti merupakan senyawa aktif yang larut dalam solven polar.

\section{KESIMPULAN}

Hasil penelitian ini mengungkapkan bahwa solven dengan perbedaan polaritas yang digunakan untuk ekstraksi juga berdampak pada jumlah kematian larva. Nilai $\mathrm{LC}_{50}$ dan $\mathrm{LC}_{90}$ ketiga ekstrak metanol; etil asetat dan kloroform berturut-turut adalah; 153,$57 ; 185,80 ; 3542,03$ ppm dan; 226,59; 274,70; 5567,24 ppm. Ekstrak metanol rimpang Z.zerumbet memiliki aktivitas larvisida yang kuat terhadap larva instar III-IV Ae.aegypti dibandingkan dengan ekstrak lainnya.

\section{DAFTAR PUSTAKA}

Begum, S.M.I., Durga A., Mary R.R., Vithiya, B.S.M., Elumalai K., 2014 Evaluation of Larvicidal Activity of Tridax procumbens (Asteraceae) Leaf Extract Against the Dengue vector Aedes aegypti and Bancroftian Filariasis vector, Culex quinquivasciatus. Indian
Journal of applied Research 4 (8) 664666.

Chien, T.Y., Chen, L.G., Lee, C.J., and Wang, C.C., $2008 . \quad$ Anti-inflamatory constituens of Zingiber zerumbet, Food Chemistry, vol 11 (3) 584-589.

Dae, S.J., Han, A.R., Park,G., Jhon, G.J., and Seo, E.K., 2004. Flavonoids and aromatic compounds from the rhizomes of Zingiber zerumbet, Archives of Pharmacal. Reseach, vol 27(4) 386-389.

Diniz, M.M.C.S.L., Henriques, A.D.S., Leandro, R.S., Aguiar, D.L., and Beserr, E.B. 2014. Resistance of Aedes Aegypti To Temephos And Adaptive Disadvantages. Rev Saúde Pública.; vol.48(5):775-782 .

Finney, D.J., 1971. Probit Analysis; A Statistical treatment of sigmoid response curve, Cambridge, 67-79.

Govindarajan, M., Ramya, A and Sivakumar, R., 2014. Mosquito larvicidal properties of Mirabilis jalapa (Nyctaginaceae) against Anopheles stepheni, Aedes aegypti, \& Culex quinfasciatus (Diptera : Culicidae) Indian J.Med.Res.438-440.

Grisales, N., Poupardin, R.,, Gomez, S.,, Fonseca-Gonzalez, I., Ranson, H., 2013. Temephos Resistance in Aedes aegypti in Colombia Compromises DengueVector Control. PLoS Negleted Tropical Diseases.; vol.7(9): e2438 110.

Hashemi, S.R., Zulkifli, I., Bejo, M.H., Farida A., and Somchit, M.N.,2008, Acute toxicity study and phytochemical screening of selected herbal aqueous extract in broiler chicken, International Journal of Pharmacology, vol. 4(5) 352-360.

Kovendan, K., Murugan, K.,Vincent, S., 2012. Evaluation of larvicidal activity of Acalypha alnifolia Klein ex Willd. (Euphorbiaceae) leaf extract against the malarial vector, Anopheles 
stephensi, dengue rector,
$\begin{aligned} & \text { Aedesaegypti and } \\ & \text { filariasis }\end{aligned}$ vancroftian
quinquefasciatus (Diptera: Culicidae),
Parasitol. Res. 110 (2): 571-81.

Marathagavalli, $\quad$ S., $\quad$ Brindha, S., Kaviyarasi.,N.S., Annadurai, B.,Gangwar, S.K., 2012. Mosquitoes larvicidal activity of leaf extract of neem (Azadirachta indica), I.J.A.B.R., vol.2(1) 138-142.

Marimuthu, G., Rajamohan, S., Mohan, R., Krisnamoorthy, Y., 2012. Larvicidal and ovicidal properties of leaf and seed extracts of Delonix elata (L)Gamble (family :Fabaceae) against malaria (Anopheles stephensi Liston) and dengue (Aedes aegypti (linn) (Diptera : Culicidae) vector mosquitoes., Parasitol Res. 111 (1) 65-77.

Mulyatno, K.C., Yamanaka, A., Ngadino, Konish, E., 2012. Resistance Of Aedes Aegypti (L.) Larvae To Temephos In
Surabaya, Indonesia. Southeast Asian Journal Tropical Medical Public Health. 2012; 43( 1), 29-33.

Murini, T., Satoto, T.B., Wahyuningsih M.S.H., 2014 Eksplorasi beberapa tanaman yang berpotensi sebagai larvisida Aedes aegypti (Dipterae : Culicidae)., dalam Prosiding Peluang dan tantangan Obat Tradisional dalam Pelayanan Kesehatan Formal, Yogyakarta, 305-309, ISBN : 978-60270191-0-2.

Prasetyowati, H., Hendri, J., Wahono, T., 2016. Status Resistensi Aedes aegypti (Linn.) terhadap Organofosfat di Tiga Kotamadya DKI Jakarta. BALABA.; 12 (1): 23-30.

World Health Organization, 2005. Guidelines forLaboratory and Field Testing of Mosqiuto Larvicides. Dikutip. dari :http://whqlibdoc.who.int/hq/2005 / WHO CDS_WHO PES_GC DPP 2005.13.pdf. 10 September 2011. 